\title{
LAS ESCUELAS DE ADULTAS EN LOS INICIOS DEL SIGLO XX: LEGISLACIÓN, CURRÍCULO Y JUSTIFICACIÓN. CASO PARTICULAR DE ORENSE
}

\section{Adult schools in the early twentieth century: legislation, curriculum and justification. Particular case of its scope in the province of Orense}

\author{
Rosa María Cid Galante \\ Universidad de Vigo \\ Correo-e:rosa@edu.xunta.es
}

Recepción: 16 de enero de 2020. Envío a informantes: 4 de marzo de 2020 Aceptación definitiva: 23 de agosto de 2020

Resumen: Las políticas educativas de comienzos de siglo xx en España se preocuparon por erradicar los problemas del analfabetismo y expansionar la educación a la población y entre sus objetivos estaba formalizar la enseñanza de adultos. Las escuelas de adultos y adultas eran una solución necesaria para los que no acudieran a la escuela primaria y no tenían los conocimientos académicos básicos. Para las mujeres era una gran oportunidad ya que presentaban una formación muy incompleta. Ahora bien, ¿podrían las escuelas de adultas, además de solucionar su mermada formación, allanarles el camino hacia la emancipación? Es la pregunta que subyace en este estudio, y para averiguarlo se revisa y examina la legislación y el currículum y se analizan las opiniones de la época sobre la necesidad de su implantación para deducir si las escuelas de adultas suponían una oportunidad para cambiar el estatus de las mujeres o, por el contrario, implicaban la permanencia de su condición social.

Palabras Clave: mujeres, escuelas adultas; legislación; currículo; Ourense.

ABSTRACT: The educational politics of beginnings of zoth century in Spain concerned for eradicating the problems of the illiteracy and extend the education to the population. The schools of adults and adults were a necessary solution for which did not attend to the primary school. For the women was a big opportunity since 
had a scarce training. Now well, they could the schools of adults allow them the way to the emancipation? To know it reviews the legislation, the curriculum and analyze the opinions of the period on the need of his implantation to deduce if the schools of adults supposed an opportunity to change the status of the women or, simply, involved the permanence of his social condition.

KEY WORDs: women; schools adults; legislation; curriculum; Ourense.

\section{Introducción}

$\mathrm{E}$

L INTERÉs POR PROMOVER la enseñanza de adultos surge en España en el XIX de la mano de las corrientes liberales preocupadas por la situación educativa del momento y por los elevados índices de analfabetismo de la población española. Es una época en la que se aprecian los cambios sobre el concepto del individuo, reconociéndole sus derechos y la posibilidad de participar activamente en los procesos políticos; y en lo económico, se veía la necesidad de formar a los obreros para aumentar la productividad fabril, lo que conllevaría un mayor desarrollo. En definitiva, la formación de los adultos se planteaba como una cuestión tan prioritaria como la educación primaria.

Sobre las escuelas de adultos contamos con diversas investigaciones que abordaron el proceso legislativo para su implantación y algún aspecto sobre su didáctica ${ }^{1}$. El presente estudio focaliza su atención en el proceso de creación de escuelas para las mujeres adultas a finales del siglo XIX y el primer tercio del xx. Los propósitos son, primero, profundizar y analizar el proceso legislativo de esta enseñanza desde que comienza a regularse hasta los aledaños de los años treinta; segundo, pulsar las opiniones e ideas sobre su implementación manifestadas en los debates, congresos y conferencias de las que daba cuenta la prensa del momento; y, por último, revisar el currículo de las escuelas de adultas comparándolo con el de sus homólogos para conocer cuál era su verdadero objetivo. Se pone fin al trabajo estudiando la realidad de la implantación de las escuelas de adultas en la provincia de Ourense valorando la aceptación que tuvieron, la implicación de los

Vid., entre otros: Salazar Salvador, José: «Las clases de adultos», Revista Educación, n. ${ }^{\circ}$ 62 (1957), pp. 74-78; MAYORdomo PÉREz, Alejandro: Educación y «cuestión obrera» en la España Contemporánea, Valencia, Nau Llibres, I98I; Flecha, Ramón; López, Fernando y Saco, Raquel: De los siglos de educación de adultos. De las sociedades de Amigos del Pais a los modelos actuales, Barcelona, Editorial Cooperativa El Roure, 1988; VV. AA.: Coloquio Hispano Francés: Clases populares, cultura, educación. Siglos XIX y XX, Madrid, Casa Velázquez, Universidad Nacional de Educación a Distancia, 1989; Rumbo Arcas, Begoña: «Política y didáctica de la educación de adultos (I82I-1939)», Sarmiento. Anuario Gallego de Historia de la Educación, n. ${ }^{\circ} 2$ (1998), pp. I85-I94; Del Valle, Ángela: «La educación de las personas adultas. Temporalidad y universalidad», Educación, n. ${ }^{\circ}$ I8 (2000), pp. I27-I55. También estudios de carácter genérico y que resultaron muy provechosos para este estudio fueron, entre otros, el de Scanlon, Geraldine M.: «La Mujer y la instrucción pública: de la Ley Moyano a la II República», Historia de la Educación: Revista Interuniversitaria, n. ${ }^{\circ} 6$ (1987), pp. 193207; Ballarín Domínguez, Pilar: «La escuela de niñas en el siglo xix: la legitimación de la sociedad de esferas separadas»; Historia de la Educación: Revista Interuniversitaria, n. ${ }^{\circ} 6$ (2007), pp. I43-168. 
LAS ESCUELAS DE ADULTAS EN LOS INICIOS DEL SIGLO XX:

docentes, la asistencia a dichas escuelas y las dificultades que entrañaba pasar de la teoría legislativa a la práctica. Por lo tanto, esta investigación se estructura en tres partes coincidentes con los propósitos que se acaban de exponer.

Para ello se emplearon diversas fuentes de estudio. Destacamos las bibliográficas, que sirvieron de base y apoyo para profundizar en el tema y conocer cuál era el enfoque de su análisis para plantear esta investigación desde una nueva perspectiva. Las fuentes periodísticas de la época cobraron aquí especial relevancia pues ayudaron a conocer las opiniones que había sobre la implantación de las escuelas de adultas y a calibrar hacia dónde se decantaban los argumentos esgrimidos. Las fuentes legislativas se emplearon para extraer lo concerniente a la regulación de la enseñanza de adultas; $y$ las fuentes primarias, en su mayor parte manuscritas, y las estadísticas fueron necesarias para conocer la implantación de las escuelas en la provincia de Ourense. Se aplicó en este estudio una metodología analíticadeductiva pues se pretendía el encuadre desde una perspectiva de género.

El estudio se encierra en el paréntesis temporal del primer tercio de siglo xx, período en el que se asiste a una nueva era educativa caracterizada por el impulso que se le imprime a la enseñanza primaria al asumir el Estado los gastos de la educación. Efectivamente, en la regencia de María Cristina y en nombre de su hijo Alfonso XIII, se procede a crear por RD de I8 de abril de 1900 el Ministerio de Instrucción Pública y Bellas Artes, siendo García Alix el primer ministro que lo encabeza ${ }^{2}$. Desde el nuevo Ministerio se va a abordar la problemática educativa con mayor rigor y dedicación que el Ministerio de Fomento y pretenderá superar el estado deficiente de la educación y erradicar los elevados índices de analfabetismo en España. Propiciará el primer movimiento de renovación pedagógica, el regeneracionismo, en los dos primeros decenios del siglo xx, con la ilusión puesta en asimilar el nivel de la escuela primaria a las nuevas tendencias educativas extranjeras (con la Introducción de la escuela graduada, la implantación de un currículo de carácter enciclopédico y el empleo de métodos de carácter intuitivo); y el segundo movimiento de renovación a partir de 1920 centrado en la creación de escuelas experimentales y planes innovadores de formación del magisterio y la aceptación de los grandes principios pedagógicos ${ }^{3}$. Para ello la Administración actuará en la mejora educativa desde un punto de vista cuantitativo, aumentando el número de establecimientos educativos, y desde el punto de vista cualitativo, paliando los problemas más gravosos que la hacían inoperante y la anquilosaban a métodos desfasados. Tanto García Alix como después el conde de Romanones en sus respectivas ideologías adoptaron medidas interesantes que se vieron

Vid. Ministerio De Educación Y Ciencia: Centenario de la fundación del Ministerio de Instrucción Pública y Bellas Artes, Madrid, Ministerio de Educación y Ciencia, 20oo; Álvarez LÁZAro, Pedro (dir.): Cien años de educación en España: en torno a la creación del Ministerio de Instrucción Pública y Bellas Artes, Madrid, Ministerio de Educación y Ciencia, 200I.

Sobre lo que consistieron y supusieron estos movimientos de renovación, así como sus etapas y características, vid. Pozo Andrés, María del Mar del: «La renovación pedagógica en España (1900-1939)", en Candeiras Martins, Ernesto (coord.): Actas del Vo Encontro Ibérico de Historia da Educaçao. Renovaçao Pedagógica, Coimbra, Alma Azul, 2005, pp. II5-I59. 
expuestas en el RD de 6 de julio de 1900 organizándose los establecimientos en escuelas públicas (párvulos, elementales y superiores) y privadas y en el RD de 26 de octubre de $1_{90 I^{4}}$, donde se ampliaba la edad obligatoria a los doce años, se incidió también en la formación docente exigiendo una preparación más rigurosa para vigorizarla, se creó un currículo unitario y común para todas las escuelas y se seleccionaron unos libros de texto y las materias a impartir ${ }^{5}$.

Por el RD de 8 de junio de i9ıo y en la RO del i6 de febrero de i9ı2 se ratificó la denominación de todas las escuelas públicas como Escuelas Nacionales de Primaria desapareciendo las connotaciones de Elementales (completas e incompletas) y Superiores ${ }^{6}$.

En la dictadura de Primo de Rivera va a haber nuevas leyes sobre la educación; como la ampliación de la obligatoriedad educativa hasta los catorce años; la ampliación de medidas para combatir el analfabetismo; control de la asistencia obligatoria de los niños y niñas a las escuelas; fomento de creación de distintos tipos de escuelas: diurnas, nocturnas, en las fábricas, etc., todas estas medidas consiguieron ir minando las elevadas tasas de analfabetismo pero los logros no fueron los esperados. Por lo demás, resultó un retroceso en las libertades y un férreo control a todos los niveles del profesorado, material escolar, escaso poder autonómico de los centros, etc. ${ }^{7}$.

Estas y otras medidas, que cumplirían objetivos tangibles de mejora educativa, no llegarían a solucionar su profunda deficiencia y además, como venía siendo habitual en España, dos fueron las instituciones que quisieron monopolizar la educación en beneficio propio: la Iglesia y el Estado. Al ser la institución eclesiástica reacia a que se le escapara un instrumento importante de adoctrinamiento mantendrá en esta época un duro pulso con el Estado por el control educativo. El objetivo prioritario para esta era extender a la sociedad sus axiomas en los cuales, el papel de la mujer, por su docilidad, era relevante en esa misión y el objetivo claro del Estado era la reproducción ideológica. Esto va a traer consigo continuas

4 Puelles Benítez, Manuel: Historia de la educación en España. De la Restauración a la Segunda República, tomo III, Madrid, Ministerio de Educación y Ciencia, 1979, pp. 170-179.

s Todas estas medidas eran muy necesarias para solucionar los problemas de la enseñanza. En este sentido, la ciudad de Ourense fue una de las primeras en reclamar en la Exposición Agrícola Nacional celebrada en Madrid en septiembre de I857 una educación gratuita en la que se facilitase el material necesario para los más pobres arguyendo que el atraso educativo era muy preocupante. Así consta en la Memoria de la Junta de Agricultura de Ourense bajo el título «Causas de las calamidades que afligen a Galicia, y modo de remediar algunas». Vid. BOP (Boletín Oficial de la Provincia), 6-4-I858 y 8-4-I858.

6 Ferrer Y Rivero, Pedro: Tratado de la Legislación de primera enseñanza vigente en España, Madrid, Librería de Sucesores de Hernando, 1906, pp. 204-205.

Vid. López Martín, Ramón: Ideología y educación en la dictadura de Primo de Rivera: escuelas y maestros, $I$, Cuadernos del Departamento de Educación Comparada e Historia de la Educación, n. ${ }^{\circ}$ I8, Valencia, Universidad de Valencia, 1994, pp. 32, 82-83; «La construcción y creación de escuelas en la España del primer tercio del siglo xx», Historia de Educación, n. ${ }^{\circ}$ I6 (1997), pp. 65-73; Conde De Romanones: "Discurso leído en la Universidad de Salamanca en la inauguración del curso académico 1902-1903», en Puelles Benítez, Manuel: Historia de la Educación en España. De la Restauración..., op. cit., pp. 352-357. 
cesiones por parte de la institución estatal que ahora cobra protagonismo y que influirán en los procesos legislativos a lo largo del dilatado período que va desde I9O2 a 1923. Por lo tanto, y a pesar de los avances experimentados en la educación, con la incorporación de la mujer en un sistema educativo regulado, tras el fenómeno de escolarización-alfabetización se va a esconder un complejo entramado de intereses con el objetivo de transmitir mensajes de reproducción de roles más que procurarle un fin en sí misma. La enseñanza primaria de esta época va a afianzar el orden establecido; mantener la discriminación sexual, salvaguardar la moral religiosa y, en definitiva, va a propugnar el modelo de una sociedad patriarcal que procedía de la centuria anterior, cuestiones que serán corregidas en los planteamientos educativos de la Segunda República.

Dentro de este panorama el presente estudio quiere abordar lo concerniente a las escuelas para adultas. No hay duda de que esta nueva oferta educativa era atractiva y necesaria para la mujer ya que, por entonces, la escolarización de muchas niñas era incompleta e irregular al considerarse suficiente que adquiriesen tan solo unas nociones básicas y rudimentarias de lectura, escritura, cálculo e historia sagrada, pues su objetivo y cometido vital era lo concerniente al mundo privado y doméstico. La transmisión de los estereotipos de la mujer como subordinada al hombre -idea principal por la que se justificaba la falta de derechosperduraba en la sociedad de la época, de carácter marcadamente conservador. El discurso hegemónico sobre la mujer en este primer tercio de siglo seguía siendo el imponerle un repliegue social e imprimirle un carácter dócil. Por tanto, no era indispensable una amplia formación en las escuelas.

A la vista de este panorama podría pensarse que las escuelas de adultas ofrecerían una estupenda oportunidad para que las jóvenes que habían abandonado la escuela ampliaran su cultura y formación y llegaran a tener cierta independencia, mas ¿realmente fue así?

\section{El proceso legislativo de las escuelas para adultas}

\section{I. Los inicios. Momentos de tanteos y poca concreción (1812-1910)}

La creación de una serie de escuelas para obreros y adultos con el fin de dar satisfacción a las necesidades que imponía la vida moderna y las reivindicaciones sociales serviría para incrementar el nivel cultural de una gran masa de población que por diversas circunstancias no había disfrutado de una educación académica. Ya la insigne Concepción Arenal fue sensible a este tema pues argumentaba que era preciso educar a las «masas» por medio de las escuelas de adultos y otros medios pues supondría una ampliación y mejora de la cultura de un pueblo ${ }^{8}$. Serían los ilustrados y los intelectuales de la Institución Libre de Enseñanza los que,

8 Correal, Narciso: «La soberanía popular y la instrucción del proletariado», El Compostelano, 22 de noviembre de 1922, p. I. 
movidos por las ansias modernizadoras, impulsarían la preocupación por una educación que permitiera, entre otras cosas, una mejora de la clase obrera.

Un leve indicio sobre el tema parece vislumbrarse en los artículos 366 y 367 de la Constitución de i8ı2 que recogían la necesidad de establecer lugares de instrucción primaria en «otros establecimientos» pudiendo estar refiriéndose a las escuelas de adultos 9 .

Artículo 366: En todos los pueblos de la Monarquía se establecerán escuelas de primeras letras, en las que se enseñará a los niños a leer, escribir y contar, y el catecismo de la religión católica, que comprenderá también una breve exposición de las obligaciones civiles.

Artículo 367: Asimismo se arreglará y creará el número competente de universidades y de otros establecimientos de instrucción, que se juzguen convenientes para la enseñanza de todas las ciencias, literatura y bellas artes.

En I8I3, los liberales vieron que era necesario ampliar la cultura del país y crearon una Junta de Instrucción Pública cuyo objetivo era hacer un estudio para reformar la educación. Esto dará origen al Informe Quintana, que recogería la preocupación por asegurar una enseñanza en todas las edades de la vida y, en lo relativo a la educación de las mujeres, en su Título XII «De la Educación de las mujeres», artículos II5-II6, hacía mención de los aprendizajes que debían recibir las adultas ${ }^{10}$.

Art. IIs. Se establecerán escuelas públicas, en que se enseñe a las niñas a leer y a escribir, y a las adultas las labores y habilidades propias de su sexo.

Art. II6. El Gobierno encargará a las Diputaciones provinciales que propongan el número de estas escuelas que deban establecerse en su respectiva provincia, los parajes en que deban situarse, su dotación y arreglo.

Así mismo, el artículo I2I del Reglamento General de Instrucción Pública aprobado en el año i82I, durante el trienio liberal de Fernando VII, recogía ese interés ${ }^{11}$. Lo importante es ir viendo que comenzaba a haber una incipiente preocupación por la creación de escuelas de adultas y que se iba materializando en la reglamentación educativa.

Posteriormente, tras el paréntesis absolutista fernandino, se da entrada a una nueva etapa de liberalismo moderado estando de regente María Cristina de Bor-

9 Constitución Española I8ı2. Título IX, http://enciclopedia.us.es/index.php/Documento:

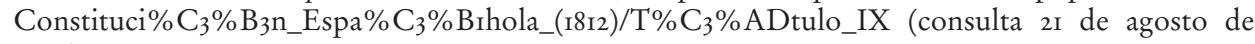
2020).

10 Informe Quintana 1913, http://www.ub.edu/ciudadania/hipertexto/evolucion/introduccion/ edu22.htm (consulta 2I de agosto de 2020). Informe Quintana. Dictamen y Proyecto de Decreto sobre el arreglo general de la Enseñanza Pública (7 de marzo de i814), http://www.ub.edu/ciudadania/ hipertexto/evolucion/textos/infquintana.htm (consulta 2I de agosto 2020).

"Vid. Rumbo Arcas, Begoña: «Política y didáctica de la educación de adultos (I82I-I939)», op. cit., p. I84; Ballarín Domínguez, Pilar: «La escuela de niñas en el siglo xix: la legitimación de la sociedad de esferas separadas», op. cit., p. I54. 
bón y, en I838, se proyectó una ley en la que se mencionaba el fomento de las escuelas de adultos. Pero el gran revulsivo vendría con la promulgación de la Ley Moyano en $1857^{12}$, dictada durante el reinado de Isabel II, que, en su artículo Io6, disponía que el Gobierno «debiera» fomentar el establecimiento de lecciones de noche o en los domingos para los adultos en las villas de io.0oo habitantes.

Art. Io6. Igualmente fomentará el establecimiento de lecciones de noche o de domingo para los adultos cuya instrucción haya sido descuidada o que quieran adelantar en sus conocimientos.

Art. 107: En los pueblos que lleguen a ro.00o almas habrá precisamente una de estas enseñanzas... ${ }^{13}$.

Según cuenta Ascarza, en cumplimiento de este precepto, se establecieron en muchas poblaciones escuelas de adultos, o bien eran voluntarias y estarían dotadas según la aquiescencia del Ayuntamiento y desempeñadas por maestros propios (serían escuelas propias de adultos), o bien serían las clases de adultos y estarían a cargo de los mismos maestros de las escuelas diurnas, mediante el pago de una gratificación ${ }^{14}$.

El tema seguirá siendo recurrente y en I868, todavía en un período liberal democrático, se plantea un nuevo proyecto de ley en el que se manifiesta un interés por elevar el nivel de instrucción primaria y de la cultura en general. En ese mismo año comienza a haber opiniones en Galicia que hablaban de la conveniencia de implantar escuelas de adultos pues, según decían, resultaba bastante factible al no requerir muchas inversiones $y$, además, la experiencia ya comenzaba a ponerse en práctica en diversas zonas como Andalucía, Aragón y Cataluña que podrían servir de modelo ${ }^{15}$.

En esta nueva visión de culturizar a la sociedad tendrán mucho que ver las ideas krausistas, introducidas en España por Fernando de Castro, y, sin duda, fueron decisivas en lo concerniente a la educación de la mujer ${ }^{16}$. La filosofía de dicho movimiento pudo haber influido para que se creasen escuelas para adultas

12 Una ley que tendría una vigencia de casi izo años hasta ser totalmente derogada en 1970. Vid. Sevilla Merino, Diego: «La Ley Moyano y el desarrollo de la educación en España», Ethos Educativo, n. ${ }^{\circ} 40$ (2007), pp. IIO-I25.

${ }^{13}$ «Ley de Instrucción Pública», Gaceta de Madrid, n. ${ }^{\circ}$ I7ı, io de septiembre de I857, p. 2.

i4 Vid. Fernández Ascarza, Victoriano: Diccionario de legislación de Primera Enseñanza, Madrid, Magisterio Español, 1924, p. 22.

is Sin firmar: «La Instrucción Pública y las escuelas de adultos», El Buscapié: Periódico Satírico de Noticias y Anuncios, n. ${ }^{\circ}$ 90, I8 de enero de 1868 , p. I.

${ }_{16}$ Fernando de Castro tuvo un especial interés por la educación de las mujeres poniendo en marcha interesantes iniciativas que abrirían nuevas perspectivas para las jóvenes. La creación del Ateneo Artístico y Literario de Señoras; la Escuela de Institutrices, pero, sobre todo, la fundación de la Asociación para la Enseñanza de la Mujer creada en Madrid el i de octubre de I87o fueron decisivas para ampliar los horizontes de las mujeres. La Asociación integraba escuelas donde se les proporcionaba una formación profesional (escuela de institutrices, comercio, correos, mecanografía...). No cabe duda de que estas iniciativas despertaron el interés por la educación de la mujer. 
como una oportunidad para fomentar la formación de las muchachas de los ámbitos provinciales y rurales liberándolas de la situación de paupérrima educación.

En el período de la Primera República la educación adulta contaba con un notable apoyo institucional y en el Proyecto de Constitución Federal de la República de 1873 se indicó que se les debía exigir a los Estados que sostuvieran escuelas de niños y de adultos de forma gratuita y obligatoria. En lo que atañe a las mujeres, entre las reformas que se iban a producir en 1876 en la enseñanza primaria, estaba la creación de las escuelas de adultas dominicales y no nocturnas, y diversas opiniones en la prensa de la época comienzan a preocuparse por el tema: ${ } i$ Convienen las escuelas de adultas y las de artes u oficios propios de la mujer? Todo lo que tienda al mejoramiento de la instrucción es conveniente; pero las primeras las suplen las dominicales, por ser peligrosas algunas veces la concurrencia de mujeres durante la noche; las segundas deben establecerse tan sólo en muy determinadas poblaciones ${ }^{17}$.

El interés por la enseñanza popular para fomentar la educación adulta quedó en un principio frenado con la llegada de la Restauración monárquica. Hasta finales del siglo XIX todas las medidas habían sido inútiles, aunque ilustres pensadores como Cossío seguían defendiendo la necesidad de organizar la enseñanza de adultos porque posibilitaría reducir rápidamente las altas tasas de analfabetismo ${ }^{18}$.

Iniciado el siglo xx las escuelas de adultos existían, aunque en número reducido. A partir de ahora se dictan diversas normativas sobre cómo y dónde debían implantarse y quién debía sufragar sus gastos ${ }^{19}$. En el caso de las escuelas de adultas el Real Decreto de 26 de octubre de I90 estableció clases dominicales en las escuelas regidas por maestras, pero no era de obligado cumplimiento ${ }^{20}$. Redundó en favor de las mujeres el hecho de que durante el reinado de Alfonso XIII se instaló el ideal de una educación femenina racional, útil e igualitaria en grados y contenidos con la masculina y se incrementó el número de centros para instruir a las jóvenes, lo que sería estimulante para las muchachas ${ }^{21}$. Aunque, obviamente, toda enseñanza para las féminas estaba sazonada de valores conservadores.

${ }_{17}$ Panero, Manuel: «Contestación a las preguntas publicadas por 'El Monitor' referentes a las reformas que reclama la legislación de la primera enseñanza», El Magisterio Español: Revista General de la Enseñanza, n. ${ }^{\circ} 560$ (1876), p. I.

18 Cossío, Manuel B.: «La reforma escolar», Revista Nacional, Madrid (I899), p. 342; reproducido en el compendio legislativo del Ministerio De Educación y Ciencia: Historia de la Educación en España, tomo III, Madrid, Ministerio de Educación y Ciencia, 1982, pp. 338-350.

19 Según el artículo 84 del RD de 6 de julio de 1900 las escuelas de adultos serían substituidas por las clases nocturnas. Los maestros de escuelas completas quedaban obligados a impartir esta enseñanza y los municipios debían consignar en sus presupuestos las cantidades necesarias para las atenciones de estas clases ( $\mathrm{RO}$ de 20 de octubre de 1900). Y por la Real Orden del 22 de febrero de I90 encarecía a los ayuntamientos la obligación de crear escuela de adultos. Vid. Fernández AscarZA, Victoriano: Diccionario de legislación de Primera Enseñanza..., op. cit., p. 22.

${ }_{20}$ Ibidem.

21 Capel Martínez, Rosa María: «Mujer y educación en el reinado de Alfonso XIII: Análisis cuantitativo", Cuadernos de Historia Moderna y Contemporánea, n. ${ }^{\circ}$ (198I), p. 234. 
LAS ESCUELAS DE ADULTAS EN LOS INICIOS DEL SIGLO XX: ROSA MARÍA CID GALANTE

En efecto, se consideraba que formar a las mujeres adultas era un bien para toda la sociedad pues se reforzaba a las madres como pilar fundamental de la familia garantizando el mantenimiento del orden establecido. Al hilo de esta idea, diversas opiniones de la época decían que la deficiente educación que las madres daban a sus hijas podría solventarse si existieran escuelas de adultas a donde acudieran las progenitoras para luego poder dar a sus criaturas los conocimientos y consejos adecuados para la misión a la que estaban abocadas, y que, evidentemente, no era otra que el matrimonio. También se reclamaba la conveniencia de que se reglara el horario de la enseñanza adulta, sugiriéndose que se adaptara lo mejor posible a cada zona ya que era de suponer que la asistencia de las jóvenes a las clases nocturnas no estaba garantizada al considerarse poco indicado que la mujer estuviera fuera del hogar en horas vespertinas ${ }^{22}$.

En relación a las escuelas de adultos supuso un avance decisivo el $\mathrm{RD}$ de 4 de octubre de 1906 (que se mantuvo con ligeras modificaciones hasta 1954) pues precisó de una manera más concreta la matrícula, la duración del curso, las horas diarias, las materias de estudio, la metodología, las actividades complementarias..., favoreciendo compatibilizar los estudios con el trabajo. Con ello se pretendía atenuar el tan grave daño del analfabetismo:

La difusión de la enseñanza primaria entre todas las clases sociales, y muy especialmente entre las clases rurales, es el empeño tenazmente perseguido por los Gobiernos, durante los últimos años, porque constituye un medio eficaz para extender la cultura popular, base indiscutible de la prosperidad en los tiempos actuales. Las Estadísticas acusan en España un considerable número de analfabetos, que, sí van decreciendo algún tanto, todavía exige por parte del Estado una campaña tenaz, insistente, incansable, para su continua y rápida aminoración [...] tan grave daño puede atenuarse con el establecimiento de las llamadas clases nocturnas de adultos ${ }^{23}$.

Pero era necesario concretar y regular las escuelas de adultas. En las Conferencias Pedagógicas que se celebraron en Lugo en 1903 en los días 19, 20 y 2I de julio, uno de los puntos que se abordaron fue la necesidad de la creación de las escuelas de adultas ${ }^{24}$. En una de las conferencias tomó la palabra la maestra de Samos, doña Micaela Mourelo, quien leyó un trabajo sobre su importancia por la necesidad de la instrucción de la mujer. Posteriormente tomó la palabra la maestra de Chantada, doña Áurea Rodríguez, que, con entusiasmo, leyó un trabajo

22 En la ponencia de la maestra de Cornudella, doña Enriqueta Anjaumá, en la Asamblea Provincial Pedagógica que se celebró en Tarragona el día 3 de agosto apelaba a que el Ministerio dictara una Real Orden para que el artículo 84 del Reglamento orgánico del 6 de julio de 1900 señalara las horas convenientes de las escuelas de adultas evitando las clases nocturnas. AnJaumÁ, Enriqueta: «Asamblea provincial pedagógica. Importancia y necesidad de la creación de escuelas de adultas, bajo el punto de vista intelectual y moral», Diario del Comercio: Órgano del Partido Liberal Dinástico, n. ${ }^{\circ} 2074,9$ de agosto de I9oI, p. I.

${ }^{23}$ «Real Decreto relativo a la escuela de adultos», La Educación, n. ${ }^{\circ}{ }_{127}, 20$ de octubre de 1906, p. I-2; Gaceta de Madrid, n. ${ }^{\circ}$ 282, 9 de octubre de 1906, p. III.

${ }^{24}$ «Conferencias», El Norte de Galicia: Diario Politico y de Información, n. ${ }^{\circ} 667,2 \mathrm{r}$ de abril de I903, p. 2. 
en el que consideraba a la mujer bajo el doble aspecto de madre y maestra de sus hijos e hizo una apología del influjo social de la mujer en todas las épocas. Abogó por la implantación de las escuelas dominicales para niñas, en lugar de nocturnas que ofrecían algunos inconvenientes ${ }^{25}$. También en otros Congresos celebrados ese mismo año, como el de Albacete, abordaron el tema de la educación de adultas argumentándose que en ellas debían enseñarse nociones de higiene, conocimientos referidos al servicio doméstico y sencillas labores propias de su sexo ${ }^{26}$.

En diferentes artículos de prensa de Galicia comienzan a aparecer interesantes opiniones solicitando la creación y organización de las escuelas de adultas. Dichas disertaciones llevaban implícito que el objetivo primordial de su implantación era que las niñas aprendiesen los rudimentos domésticos, no tanto adquirir elevados conocimientos intelectuales y culturales. Por lo tanto, se concebía la importancia de dichos establecimientos para ampliar en algo la cultura de las mujeres y potenciar su condición femenina, en definitiva, apuntalar la permanencia de su rol de ser buenas esposas, madres e hijas.

Tenemos escuelas de adultos, cuya utilidad es innegable, pero ¿’Por qué no han de establecerse también escuelas de adultas nocturnas o dominicales, donde las jóvenes que ya abandonaron la escuela primaria puedan recordar y ampliar los conocimientos adquiridos? ¿No podría, además, en estas escuelas enseñarse el arte de cocina y confección, en sus múltiples manifestaciones, tanto de la modistería y sastrería como de flores y bordados? Suele procederse con demasiada ligereza durante la vida escolar, y unas veces por culpa de la alumna y otras por culpa de sus padres, acontece con frecuencia dejar la niña la escuela primaria sin haber aprendido el manejo de la aguja, hilvanar, pespuntear... [...] ¿qué esperanza de bienestar puede esperar una pobre niña que no aprenda el arte de cocinar o coser?...27.

Las normativas indicaban que las clases nocturnas para los jóvenes varones tenían por objeto ampliar y perfeccionar la educación de los mayores de is años dada en las escuelas primarias diurnas, y con respecto a esto no había nada que objetar pues era lo obvio en esta época. En cuanto a las escuelas para adultas las opiniones se decantaban por defender que no debían tener el mismo alcance y extensión que las de los chicos y, por lo tanto, era excusable tanta exigencia y planificación para ponerlas en funcionamiento debiendo, simplemente, sujetarse a las condiciones y circunstancias de cada lugar ${ }^{28}$. Pero, por fin, se dicta una ley. En efecto, la RO de 1907 en su artículo I4 estimulaba a los ayuntamientos a crear

" «Conferencias Pedagógicas», El Norte de Galicia: Diario Político y de Información, n. ${ }^{\circ}$ 73I, 22 de julio 1903 , p. 2.

${ }_{26}$ Memoria leída en el Congreso Pedagógico Nacional de Albacete, La Escuela Moderna,I de octubre de 1903, pp. 69-7I.

27 Solana, Ezequiel: «Instituciones escolares. Escuelas de adultas», La Correspondencia Gallega: Diario de Pontevedra, n..$^{\circ}$ 5463, 27 abril I908, pp. I-2.

${ }_{28}$ «De actualidad. De las últimas instrucciones sobre adultos», El Magisterio español: Revista General de la Enseñanza, n. ${ }^{\circ}$ 3048, I4 de noviembre de 1906, pp. 534-535. 
escuelas de adultas ${ }^{29}$. Es evidente que alentar o animar es lo opuesto a obligar, por lo que, casi con seguridad, se puede decir que dicha medida no obtendría grandes resultados.

Por ello, debido a que estas normativas y reglamentos no precisaban lo suficiente, no era extraño encontrar comentarios en los que se criticaba que las autoridades pertinentes no se preocuparan de la educación para las mujeres adultas:

La creación legal de las escuelas de adultas en España es relativamente moderna. Nuestros legisladores tuvieron en olvido imperdonable por largo tiempo este fecundo manantial de cultura femenina, que pudo ser explotado mucho antes en favor de la mujer del pueblo si las clases referidas se hubieran establecido al mismo tiempo que sus similares las de adultos. Sí; en ese manantial debieron ya purificarse de su analfabetismo y su ignorancia varias generaciones [...] y... acaso muchos males que la sociedad actual lamenta, hubiéranse (sic) evitado... En nuestra patria querida se comenzó la creación legal de las escuelas de adultas, aunque no de un modo terminante, en el Real Decreto del 26 de octubre de r9or, y de igual manera se ha continuado en el Real Orden del 28 de octubre de r9o6, y sobre todo en el del I de enero de 1907. Todavía esto no es suficiente... ${ }^{30}$.

\subsection{Una mayor concreción legislativa sobre las escuelas de adultas por el RD de $\mathrm{I} 9 \mathrm{II}$}

Tendremos que esperar al RD del II de mayo de I9II para encontrar una reglamentación específica de la educación para adultas en la que se establecían los programas, currículos, docencia, matrícula, horarios... Dicho Real Decreto fue por iniciativa de Rafael Altamira, director general de Enseñanza Primaria, organismo creado el I de enero de i9i sin vinculación política. Altamira, un hombre de profunda y amplia cultura muy ligado a la ILE, fomentaría la escuela de adultas, aparte de otras medidas muy interesantes para fortalecer la formación de la mujer y darle la oportunidad de adentrarse en ámbitos por ahora inéditos como era la inspección educativa, siendo el promotor de la creación del Cuerpo Femenino de Inspectoras en 1913, refrendada por el entonces ministro de Instrucción Pública, Antonio López Muñoz ${ }^{31}$.

El Real Decreto del Ministerio de Instrucción Pública y Bellas Artes indicaba que el objeto de las escuelas de adultas era ampliar y perfeccionar la educación dada en las escuelas de primaria a las jóvenes mayores de i2 años y proveer de la

29 Fernández Ascarza, Victoriano: Diccionario de Legislación de Primera Enseñanza..., op. cit., p. 23 .

30 Gálvez Delgado, Concepción: «Las escuelas de adultas en Madrid», La Escuela Moderna, I de enero de I9IO, p. 6.

${ }_{31}$ Fernández Ascarza, Victoriano: Diccionario de Legislación de Primera Enseñanza..., op. cit., p. 32; SCANLON, Geraldine M.: «La mujer y la instrucción pública: de la ley Moyano la II República», Historia de la Educación, op. cit., p. 204; Flecha GARCíA, Consuelo: «La Inspección de Primera Enseñanza en el primer tercio del siglo xx: modelos, contextos y protagonistas», Historia Caribe, volumen XIII, n. ${ }^{\circ} 33$ (20I8), pp. I79-2I8. 
enseñanza a las mujeres que por cualquier motivo no habían cursado estudios en la edad reglamentada. Dichas clases se impartirían durante todo el curso los jueves y los domingos de cada semana en horas de tarde o de noche:

Se darán en horas de tarde o de la noche, de conformidad con las costumbres de las localidades y la jornada habitual del trabajo de las mujeres, se estimen como más oportunas en cada sitio. Al efecto las Juntas Locales, de acuerdo con las maestras, propondrán a los respectivos inspectores el horario que consideren más conveniente; en caso de disconformidad, resuelve la Junta Provincial, oyendo al Inspector ${ }^{32}$.

El hecho de tener que impartir clases los domingos suscitó las quejas por parte de algunas maestras como la pronunciada por la maestra Dolores García: «¿Por qué razón la Maestra ha de ver anormalizada (sic) la libertad dominical que le queda después de los seis días de lucha...?»33. Dejaba claro que para ella las clases para adultas eran muy justas, necesarias y beneficiosas, pero proponía que se establecieran los jueves y los sábados.

En relación a los programas se indicaba que serían los mismos de las escuelas primarias recalcando que la finalidad especial de esta enseñanza era desarrollar la vida femenina dentro y fuera del hogar. Por lo tanto, los objetivos de esta enseñanza no eran otros que los de ampliar un poco la cultura de las mujeres sin la pretensión de cambiar el rol que por tradición se les tenía asignado. Es más, se pretendía acentuar su condición de entrega a la vida doméstica como buena administradora. En la disciplina de lengua se trabajaría la lectura práctica sobre modelos de libros de economía doméstica, viajes, historia, literatura, higiene (especialmente del hogar y de la infancia) y ciencias naturales. Los ejercicios de escritura se centrarían en redacción de cartas, recibos, instancias y documentos de uso frecuente en la vida familiar y social. En aritmética se resolverían problemas variados sobre la vida cotidiana de salario, ahorro, uso de medidas y pesos. Las nociones de geometría deberían reducirse a labores femeninas, bordados, costura y corte de ropa. En definitiva, se exigía una orientación práctica y de carácter marcadamente femenino ${ }^{34}$. La duración de las clases no debía ser inferior a dos horas y las materias se distribuirían en los días semanales establecidos.

En relación a las maestras que debían impartir en estas escuelas, el Real Decreto de i9ı disponía que fueran las mismas del diurno y que, cuando acreditaran la puesta en funcionamiento de la escuela para las adultas, obtendrían una gratificación ${ }^{35}$. Los Consistorios podían dar una cantidad mayor en concepto de aumento voluntario.

32 «Las reformas en la enseñanza», El Diario de Pontevedra: Periódico Liberal, n. ${ }^{\circ}$ 8III, 26 de mayo de I9II, p. 3 .

33 García Álvarez, Dolores: El Magisterio español: Revista General de la Enseñanza, n. ${ }^{\circ} 3599$, I de junio de I9II, p. 886.

${ }_{34}$ Fernández Ascarza, Victoriano: Diccionario de legislación..., op. cit., p. 33.

${ }_{35}$ Las gratificaciones a las maestras que impartían en las clases de adultas suponían tan solo un tercio de lo percibido por los maestros que daban en adultos. 
En lo referente a la formalización de la matrícula de alumnas, el RD establecía que había que realizarla quince días antes de que comenzara el curso. Podían inscribirse todas las alumnas que lo precisaran y tuviesen i2 años, pero la matrícula nunca podría exceder de 40 niñas, habida cuenta de la capacidad del local. En caso de que hubiera más demanda tendrían preferencia las alumnas que ya tenían algún conocimiento de lectura y escritura entre 12 y 20 años y las que tuvieran más de los 20 serían matriculadas si había plaza.

En relación al material escolar, el RD establecía que la maestra tenía que hacer una petición proporcional al número de alumnas que habían asistido todo el curso en años anteriores. El gasto iría destinado al pago de la luz, calefacción, plumas, papel, tinta... En caso de que los presupuestos no llegaran, debería el Ayuntamiento complementarlos. En cuanto los libros y cuadernos debían ser adquiridos por las alumnas.

Este $\mathrm{RD}$ recogía la posibilidad de que las personas del lugar colaboraran con las escuelas. Personas que, por su formación o preparación, podían enseñar mucho a los educandos y a los propios docentes por medio de conferencias o disertaciones de carácter práctico sobre economía doméstica: cocina, corte y confección de vestidos, higiene, industrias domésticas y atenciones en la casa: «En todos los pueblos que fuera posible, se procurará asociar a la enseñanza de adultas las personas que por su profesión y su cultura puedan ser colaboradoras de aquella obra educativa» ${ }^{36}$.

\subsection{Nueva categoría de las escuelas de adultas: la enseñanza complementaria. Un paso importante hacia una preparación más profesionalizada}

Las escuelas de adultas van a sufrir una transformación en su consideración, pasando a tener una nueva orientación según el RD del 4 de abril de igr3 y la Orden del 7 de junio de i9iz. La formación quiere perfeccionarse en un momento en el que cada vez es más creciente la incursión de las mujeres en los estudios medios, superiores e incluso profesionales. En este contexto nuevo para la mujer, se quiere organizar la enseñanza para las adultas en dos clases. La primera estaría destinada a impartir enseñanza a mayores de I2 años analfabetas y correría a cargo de una auxiliar. La segunda clase se dedicaba a las jóvenes que iban a ampliar la instrucción primaria y que deseaban iniciarse en los conocimientos y prácticas de alguna competencia semiprofesional que les sirviera para el desempeño de una ocupación y obtener un medio de vida. Este grupo estaría a cargo de la maestra directora (que pasarían a cobrar igual incluso que sus homólogos, ioo pesetas mensuales). Todas las clases serían diarias de seis a ocho de la noche de octubre a mayo. Las primeras escuelas de adultas que se crean son las de Madrid, Barcelona, Valencia y Granada.

\footnotetext{
${ }_{36}$ Gaceta de Instrucción Pública y Bellas Artes, 20 de noviembre de I9II, p. 7.
} 
En i915 un Real Decreto alude a que las escuelas de adultas graduadas estarían organizadas en dos grupos y que había que crear en las capitales de distrito universitario escuelas complementarias similares a las que se habían abierto en Madrid y Barcelona. El Distrito Universitario de Santiago contaría con un establecimiento de esta categoría en su capital, Santiago, instalándose en la Escuela Nacional del Hospitalillo en noviembre de 1915. Comenzó a funcionar a pleno rendimiento y las clases de cultura general eran impartidas por las maestras de la escuela y las específicas se cubrían por concurso; así, en la plaza de Corte y Confección comenzó como profesora doña Elvira Santiso y García y en la de Dibujo Geométrico y artístico doña María Taboada Deus, maestras especializadas que cobrarían un sueldo de 2500 pesetas anuales ${ }^{37}$. Para ser profesora en las escuelas de adultas recientemente creadas había que pasar una oposición que constaba de tres ejercicios, dos prácticos y uno oral, ante un tribunal compuesto por una profesora de la Escuela Superior del Magisterio, dos profesoras de la Escuela Normal y dos maestras de escuela ${ }^{38}$. Esto demuestra que el personal docente era especializado y gozaba de mayor categoría y consideración.

Pero para algunos sectores el hecho de crear una escuela de adultas en cada capital de distrito era una ridiculez y se reclamaba una escuela de adultas en cada pueblo de España pues solo de esta manera todas las mujeres gozarían de los beneficios de esta enseñanza ${ }^{39}$ :

Suscribimos sin reservas el siguiente artículo de nuestro distinguido colega madrileño «El Magisterio Español», acerca de estas relumbrantes escuelas.

Casi inadvertido ha pasado el Decreto creando varias Escuelas de adultas en capitales de distrito universitario. Se gastan en ellas 200.000 pesetas que destinaron las Cortes a este servicio y que todos creíamos se destinarían a modestas clases servidas por Maestras nacionales. Pues no ha sido así, en lugar de las cuatrocientas clases a 500 pesetas de gratificación, o más clases todavía, en pueblos modestos, donde hace falta fomentar la cultura de la mujer, se crean varias Escuelas lujosas.

Para que se vea que no somos nosotros los que censuramos, he aquí lo que dice nuestro colega «La Asociación» de Teruel:

Por muy bien dispuesto que se tenga el ánimo para aplaudir, no hay medio de elogiar la obra realizada por el Ministerio de Instrucción pública, sin hacer traición a sus propias convicciones. Se consignan en los presupuestos 200.000 pesetas para la creación de clases de adultas, con la finalidad de facilitar la propagación de la cultura popular de la mujer, y cuando todas esperábamos que se invertiría dicha cantidad en crear 400 clases, por lo menos -pues hay cantidad suficiente para tan beneficiosa reforma- sale un pomposo Real Decreto creando cuatro clases en cada una de las capitalidades de los distritos universitarios.

¿Pero hay quien pueda creer que la cultura general de la mujer va adelantar ni siquiera un paso con esta reforma? ¡TREINTA Y OCHO CLASES DE ADULTAS

37 El Correo de Galicia, 3 de noviembre de I9I5, p. 2; El Correo de Galicia, 20 de diciembre de I917, p. 2.

${ }^{38}$ «Instrucción Pública», La Región, 25 de junio de 1915, p. 2.

39 Sin firmar: «Campaña pro cultura», El Magisterio español: Revista General de la Enseñanza, n. ${ }^{\circ} 5655,3$ de julio de 1919 , p. I. 
PARA TODA ESPAÑA se han creado por el Real Decreto que acaba de dictarse! ¡Valiente empuje va a recibir la cultura popular de nuestra nación con tan ridícula reforma!

Pero no hay que sobresaltarse, en cambio se han creado, además, dos clases especiales, una de Corte y otra de Dibujo, con Profesoras especiales dotadas con I500 pesetas.

¡Qué alejados se hallan de la realidad los señores director general y ministro! Eso no es aprovechar el dinero en cosas útiles, es derrocharlo superfluamente. Las Maestras nacionales encargadas de las clases de adultas tienen suficiencia para dar lecciones de Corte y de Dibujo, señores Bullón y Esteban Collantes... ${ }^{40}$.

No será hasta unos años más tarde cuando esta demanda de ampliar la oferta escolar adulta se materialice en el Real Decreto del 25 de septiembre de 1922 y Real Orden de 30 de noviembre de $1922^{41}$. Es obvio que esta nueva concepción de las escuelas de adultas solo era factible en las capitales de distrito pues es donde había una demanda considerable de alumnas ya que la vida urbana permitía a las mujeres ampliar sus posibilidades laborales. Por el contrario, en los pueblos aún no había visos de crearse ni siquiera las elementales para las chicas pues el entorno ayudaba poco a fomentar expectativas.

Así que, a pesar de las leyes y normativas, la realidad iba a otro ritmo. Esta atonía a la hora de crear escuelas de adultas motivó que en la cuarta sesión del Gran Congreso Certamen Pedagógico celebrado en Lugo en noviembre de 1923 se abordara el tema con mucha seriedad y profundidad. Destacaron como ponentes Silva de Castro y la señorita Castrillón, maestra de Navia de Suarna en Lugo, quienes reclamaron que las escuelas de adultos y adultas se hiciesen obligatorias en todas las aldeas o, al menos, que hubiera la posibilidad de que se crearan escuelas ambulantes para dar cursos prácticos de enseñanza doméstica en las aldeas a las niñas de quince a veinte años de edad durante dos o tres meses ${ }^{42}$.

Las demandas al Ministerio eran continuas y crecían en exigencia como las llevadas a cabo por la Asamblea de Maestras Especiales de las escuelas de adultas que, además de pedir una escuela adulta para cada pueblo, también solicitaban que se convirtieran en complementarias, con ello garantizaban una oportunidad para todas las mujeres (urbanas y rurales) y la oferta tendría un rango superior y con personal propio ${ }^{43}$.

Estas demandas resaltaban que la finalidad de la enseñanza para las mujeres adultas era la de perfeccionar su condición femenina, lo cual, sin descartar la importancia de ampliar la cultura de las chicas, desanima pensar que ello no condujera a una oportunidad para romper los moldes sociales y cultuales a los que estaba sujeta.

40 El Maestro De Zaín: «Las escuelas de adultas», La Región, in de julio de i9i5, p. I.

Sin firmar: El Sol, 23 de junio de 1926, p. 2.

42 Silva de Castro: «Gran Congreso Certamen Pedagógico», La Zarpa, 4 de noviembre de I923, p. I.

${ }_{43}$ «Asamblea oficial de las profesoras especiales de adultas», El Progreso, n. ${ }^{\circ} 6365,2$ de julio de I926, p. 2. 
Por lo tanto, durante todo este período, y a pesar del transcurso por épocas de gobiernos liberales menos refractarios a las ideas modernas sobre la condición femenina, se supedita la enseñanza de adultas a la formación de una mujer tradicional, acentuada todavía más durante la dictadura de Primo de Rivera. Aunque se abre la posibilidad de que la mujer pueda adquirir una formación profesional en ocupaciones propias para ella y socialmente aceptadas, la base fundamental era formarlas manteniendo su condición de dependencia y subordinación.

\section{Currículum escolar. Más de lo mismo: preparar a las mujeres para la vida doméstica}

Las materias de estudio son un reflejo de los objetivos que pretendía esta enseñanza. Si bien las asignaturas eran prácticamente las mismas para los hombres y las mujeres, diferían en el enfoque y los contenidos que se impartían en cada una de ellas. Según el Real Decreto de 1906 se disponían las materias para las escuelas de adultos y en el Real Decreto de i9i las materias para las escuelas de adultas (Cuadro I).

CuAdro i. Materias curriculares de las escuelas de adultos para las alumnas y los alumnos

\begin{tabular}{|c|c|}
\hline $\begin{array}{l}\text { Escuelas de adultas } \\
\text { Real Decreto de I9II }\end{array}$ & $\begin{array}{l}\text { Escuelas de adultos } \\
\text { Real Decreto de } 1906\end{array}$ \\
\hline $\begin{array}{l}\text { Lengua castellana } \\
\text { - Lectura: sobre libros de economía } \\
\text { doméstica, viajes, historia, litera- } \\
\text { tura, higiene, especialmente la del } \\
\text { hogar y de la infancia; ciencias natu- } \\
\text { rales, etc., acomodados al grado de } \\
\text { cultura. } \\
\text { - Escritura: Letra clara y corriente } \\
\text { con ejercicios para escribir cartas, } \\
\text { recibos, instancias y documentos } \\
\text { frecuentes en la vida familiar y so- } \\
\text { cial. Recomendable llevar un diario } \\
\text { en el que apunten los trabajos del } \\
\text { aula. } \\
\text { - Idioma nacional. Con métodos } \\
\text { prácticos y con ausencia de toda re- } \\
\text { gla teórica, suprimiéndose todo es- } \\
\text { tudio teórico gramatical. }\end{array}$ & $\begin{array}{l}\text { Lengua castellana } \\
\text { - Lectura sobre libros de Instrucción } \\
\text { Cívica que enaltezcan el sentimiento } \\
\text { de la Patria y el respeto a las leyes y } \\
\text { a la propiedad. Lecturas de instruc- } \\
\text { ción agrícola que expongan proce- } \\
\text { dimientos modernos de cultivo; la } \\
\text { forma de organizar y funcionar cajas } \\
\text { rurales de ahorro, de crédito, sindi- } \\
\text { catos agrícolas... Se suprimirán los } \\
\text { libros de cuentos. } \\
\text { - Escritura: letra clara y corriente. } \\
\text { Ejercicios de copia de muestras y } \\
\text { dictados. Redacción de cartas, docu- } \\
\text { mentos de uso frecuente o probable. } \\
\text { Métodos prácticos escapando de es- } \\
\text { tudios teóricos-gramaticales, limi- } \\
\text { tándose a la corrección de faltas de } \\
\text { ortografía. }\end{array}$ \\
\hline
\end{tabular}




\begin{tabular}{|c|c|}
\hline $\begin{array}{l}\text { Aritmética } \\
\text { - Problemas variados y concretos es- } \\
\text { capando de ejercicios Abstractos y } \\
\text { reduciendo las reglas. Los problemas } \\
\text { tratarán sobre pesas y medidas, ope- } \\
\text { raciones necesarias para la vida do- } \\
\text { méstica, de contabilidad del hogar. }\end{array}$ & $\begin{array}{l}\text { Aritmética } \\
\text { - Problemas variados y concretos. } \\
\text { Problemas concretos de la vida co- } \\
\text { tidiana aplicados a compras y ven- } \\
\text { tas, intereses y préstamos; gastos en } \\
\text { el buen cultivo, cálculos del que se } \\
\text { pierde en ociosidad, el peligro de los } \\
\text { préstamos usurarios... }\end{array}$ \\
\hline Geometría & Geometría \\
\hline $\begin{array}{l}\text { Se limitarán a conocimientos de la vida } \\
\text { corriente, labores femeninas, dibujos } \\
\text { con aplicación de estas, corte de ropa } \\
\text { blanca y vestidos y otras aplicaciones } \\
\text { semejantes. }\end{array}$ & $\begin{array}{l}\text { Se limitarán a resolver problemas de } \\
\text { áreas, ejercicios de agrimensura, unida- } \\
\text { des agrarias. }\end{array}$ \\
\hline Ciencias físicas, químicas y naturales & Ciencias físicas, químicas y naturales \\
\hline $\begin{array}{l}\text { Explicaciones sencillas de los fenóme- } \\
\text { nos de la naturaleza. } \\
\text { Principios de higiene individuales y } \\
\text { para la casa vivienda, insistiendo en los } \\
\text { cuidados especiales que su importancia } \\
\text { requiera. }\end{array}$ & $\begin{array}{l}\text { Observación de la naturaleza y dar ex- } \\
\text { plicación sencillas a los fenómenos na- } \\
\text { turales. } \\
\text { Explicaciones sobre clases de tierras, } \\
\text { nutrición, desarrollo de las plantas, fun- } \\
\text { cionamientos de las prácticas agrícolas. } \\
\text { La formación en esta área debe refutar } \\
\text { preocupaciones, falsas asociaciones de } \\
\text { ideas, errores y supersticiones. }\end{array}$ \\
\hline Geografía & Geografía y dibujo \\
\hline $\begin{array}{l}\text { Ligeras nociones de España e Historia } \\
\text { Natural }\end{array}$ & $\begin{array}{l}\text { El profesor puede impartirlas si lo con- } \\
\text { sidera oportuno. }\end{array}$ \\
\hline
\end{tabular}




\begin{tabular}{|l|l|}
\hline Corte y confección & $\begin{array}{l}\text { Rudimentos de derecho y educación } \\
\text { cívica } \\
\text { Se explicará con preferencia y ampli- } \\
\text { tud en las escuelas de adultos. Versa- } \\
\text { rán sobre las instituciones jurídicas } \\
\text { fundamentales exponiendo la función } \\
\text { importante del sufragio universal y el } \\
\text { deber social de los ciudadanos de hacer } \\
\text { uso del voto en conciencia. } \\
\text { Valoración del servicio militar; de la } \\
\text { Nación; de la Constitución; el valor del } \\
\text { orden el progreso... } \\
\text { Esta materia debe despertar el espíritu } \\
\text { progresivo de las instituciones jurídi- } \\
\text { cas, sociales y el convencimiento de } \\
\text { la convivencia para todos para formar } \\
\text { buenos españoles. }\end{array}$ \\
\hline
\end{tabular}

Fuente: Elaboración propia a partir de Fernández Ascarza, Victoriano: Diccionario de legislación de Primera Enseñanza, Madrid, Magisterio Español, I924.

La legislación resaltaba que no había que recargar las lecciones con largas explicaciones pidiéndose concreción y brevedad en las mismas y, como el propio texto indicaba, la enseñanza debía ser «de índole primaria», es decir, básica. El enfoque debía ser lo más práctico posible para que tuviera su aplicación en la vida.

El programa curricular recoge con claridad meridiana los principios de preparar a las mujeres para la vida casera pues las alumnas estaban en la edad de ser inmediatamente casaderas. De ahí que se incidiese en el aprendizaje de la economía doméstica con la práctica de los cálculos y la resolución de problemas; la higiene del hogar; nociones de puericultura; aprendizaje y práctica de geometría para aplicar a las labores de costura... He ahí el contraste entre lo exigido para unos y para las otras, mientras el propósito para las jóvenes era que aprendiesen cuestiones de carácter muy rudimentario y casero, para los hombres primaban los aprendizajes para la vida laboral, los negocios y transacciones cotidianas.

En ris3 se produce un cambio en la consideración de las escuelas de adultas y se distribuye al alumnado en dos grupos con un carácter complementario, en uno estarían las alumnas que no estuvieron escolarizadas y eran analfabetas, las cuales recibirían una formación básica y elemental de cultura general atendiendo también a aquellas nociones ligadas a su condición femenina (economía doméstica, puericultura). Al otro grupo acudirían las que querían ampliar su cultura; aprender nociones de idioma extranjero, el francés, y además adquirir conocimientos de formación profesional como mecanografía, taquigrafía, comercio, corte y confección -lo que vendría a recordar, aunque a una escala menor, aquellas escuelas 
LAS ESCUELAS DE ADULTAS EN LOS INICIOS DEL SIGLO XX:

LEGISLACIÓN, CURRÍCULO Y JUSTIFICACIÓN. CASO PARTICULAR DE ORENSE

ROSA MARÍA CID GALANTE

de la Asociación para la enseñanza de la Mujer del Krausismo-, dándoles acceso a desempeñar ciertos oficios como modista, costurera, secretaria, dependienta..., en definitiva, un cierto porvenir y nuevos horizontes.

CUADRO 2. Materias curriculares para las alumnas en $\mathrm{I} 9 \mathrm{I3}$

\begin{tabular}{|l|l|}
\hline \multicolumn{1}{|c|}{ Clases a chicas analfabetas } & \multicolumn{1}{c|}{ Clases para ampliar conocimientos } \\
\hline Lectura & Cultura general: tres horas semanales \\
\hline Escritura & Francés: tres horas semanales \\
\hline Cálculo & Mecanografía: seis horas semanales \\
\hline Economía doméstica & Taquigrafía: seis horas semanales \\
\hline Conversaciones sobre higiene & $\begin{array}{l}\text { Prácticas comerciales: con iniciación en } \\
\text { la correspondencia y documentos mer- } \\
\text { cantiles }\end{array}$ \\
\hline Puericultura & $\begin{array}{l}\text { Visitas a museos y establecimientos } \\
\text { mercantiles }\end{array}$ \\
\hline Historia y geografía & \\
\hline Literatura & \\
\hline Cuanto & \\
\hline $\begin{array}{l}\text { Excursiones y visitas a los museos los } \\
\text { domingos }\end{array}$ & \\
\hline
\end{tabular}

Fuente: Elaboración propia a partir de Fernández Ascarza, Victoriano: Diccionario de legislación de Primera Enseñanza, Madrid, Magisterio Español, 1924.

En I9I5 se van a establecer clases de adultas en varias capitales de provincia, entre ellas Santiago ${ }^{44}$. Las escuelas complementarias de adultas suponían un concepto nuevo para la formación de las mujeres ya que los aprendizajes eran más especializados, por ello resultaban ser demandados y con grande afluencia de alumnado (Fotografías i y 2$)^{45}$.

44 También en la de Santiago habrá dos grupos, en el primero se impartía lo mismo que en el resto de las escuelas de adultas de los demás distritos, pero en el segundo variaba un poco y se daban clases de corte y confección de prendas, dibujo geométrico y artístico y ampliación de la cultura general y no se impartían mecanografía y taquigrafía. Es interesante resaltar que en septiembre de i928, por iniciativa de la Institución de Acción Católica y siendo presidenta doña María Barcón de Falero, se abrieron clases gratuitas para las jóvenes santiaguesas para aprender Geografía, Contabilidad, Francés, Taquigrafía, Mecanografía, Labores y Religión. Vid. El Correo Gallego, 27 de septiembre de 1928 , p. I.

${ }_{45}$ Por estos años también se crearon instituciones paralelas para formar a las muchachas adultas, nos referimos a las escuelas profesionales para jóvenes obreras que dispensaban una formación enfocada a lo laboral, Vid. VÁzQuez Ramil, Raquel: La Institución Libre de Enseñanza y la Educación de la mujer en España: La Residencia de Señoritas (I915-1936), Betanzos, A Coruña, Lugami, 200I. 
LAS ESCUELAS DE ADULTAS EN LOS INICIOS DEL SIGLO XX:

Fotografías i y 2. Escuelas de adultas de Madrid.

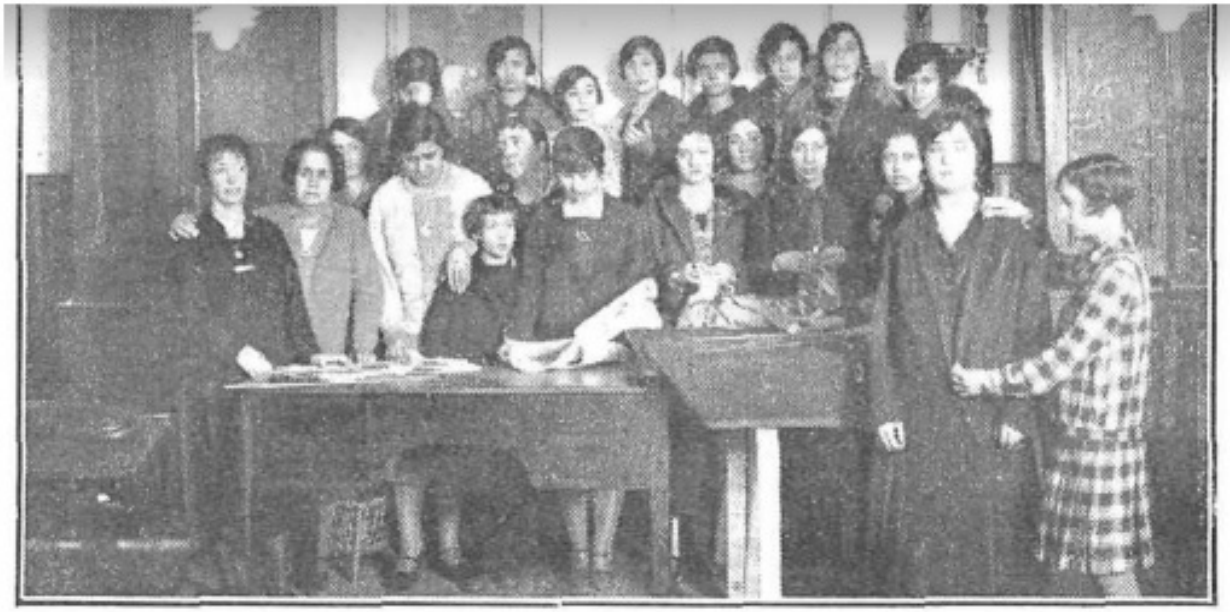

Profesuras y alumas de la clase de corte y confección

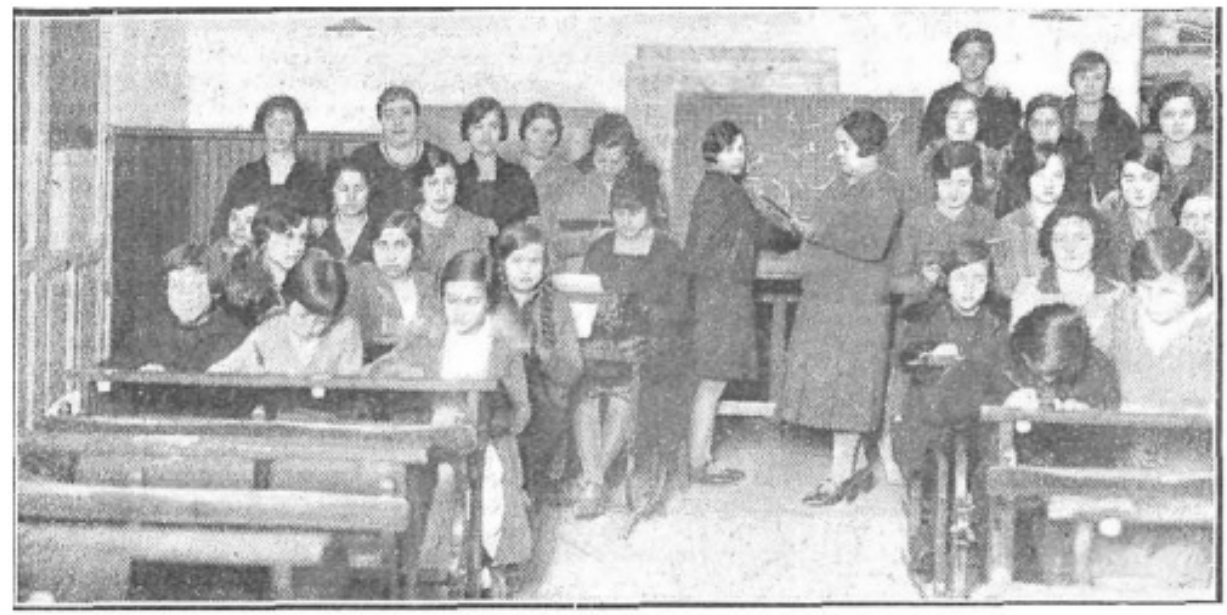

Profesoras y alumnas de la clase de Mecanografia y Taquigrafi

Fuente: Nuevo mundo (Madrid), 20 de abril de i928, p. 4.

En estos centros estaba garantizada la adquisición de valores cívicos, éticos y morales, aunque la asignatura de Religión no estaba incluida en el programa de estudios. Según el artículo 2 del Real Decreto del 4 de abril de I9I3 se crean en Madrid y Barcelona las escuelas de adultos y en sus currículos no se contemplaba la 
LAS ESCUELAS DE ADULTAS EN LOS INICIOS DEL SIGLO XX:

LEGISLACIÓN, CURRÍCULO Y JUSTIFICACIÓN. CASO PARTICULAR DE ORENSE

ROSA MARÍA CID GALANTE

formación religiosa ${ }^{46}$. Esto provocó una fuerte reacción por parte de los sectores más conservadores ya que la enseñanza de la Doctrina Cristiana tenía unas raíces muy arraigadas en un país de firme confesionalidad pues la Iglesia siempre ejerció un gran influjo en la educación.

La Gaceta comienza a darnos ya el plan completo de la Institución Libre de Enseñanza. Tres disposiciones enteramente laicas se han dado en tres o cuatro días. [...] La otra disposición se contrae a la creación de escuelas de adultas y en sus programas ya no figura la asignatura de Religión, es decir, que antes de dar el tan debatido decreto se ha planteado por una disposición oficial la enseñanza neutra. ¿Se han enterado de esto los católicos? ${ }^{37}$.

El tema seguía dando de qué hablar y, después de que se aprobase la enseñanza laica en las escuelas de adultas, la afectación fue en aumento:

[...] Nos referimos a la orden de 7 de junio último, implantado de un modo oficial y obligatoria la escuela laica, la escuela sin Dios, y lo que es más grave, la escuela sin Religión para la mujer de la clase media.

Esta es otra gravísima herida causada a la Iglesia y a la tradición española.

Desde esta fecha, en las escuelas para adultas, contra lo dispuesto en la ley de I857, no se estudiará ni Catecismo ni Historia Sagrada, y, sin embargo, estas escuelas se denominarán escuelas nacionales.

Esta orden de la Dirección General de Primera Enseñanza, publicada en la Gaceta del día is del pasado Junio y cuya base está en el Real Decreto de 4 de Abril que apareció en la Gaceta del 5 del mismo mes, es, sin duda alguna, la disposición más grave que contra los sentimientos religiosos se ha llevado al diario oficial en estos últimos años... ${ }^{48}$.

Los sectores católicos estaban indignados por la desatención de la enseñanza del Catecismo ya que educaba a la mujer en la virtud, el decoro y la fe. Pero no faltaron otros comentarios que no veían mal que no figurara la materia de Religión en las escuelas de adultas. Indicaban que dichas escuelas tenían unas características excepcionales pues estaban destinadas a las jóvenes mayores de doce años que querían ampliar los conocimientos de la enseñanza elemental o adquirir nuevos aprendizajes y era de suponer que el Catecismo ya lo habían aprendido en el tiempo que asistieran a la enseñanza elemental.

${ }^{46}$ Sobre la asignatura de la Religión en los currículos escolares en la historia de la educación en España vid. Puelles Benítez, Manuel de: «Religión y escuela pública en nuestra historia: Antecedentes y procesos», Bordón, vol. 58, 4-5 (2006), p. 524; Rodríguez Acevedo, Cruz Javier: $L a$ Religión como asignatura no confesional, Tesis de doctorado dirigida por Rafael Palomino Lozano, Madrid, Universidad Complutense de Madrid, Facultad de Derecho, 2015, pp. 193-194.

47 Sin firmar: «El laicismo en acción», La Voz de la Verdad. Diario Católico antiliberal, in de abril de i9i3, p. I.

${ }_{48}$ Thyresias: «El sectarismo en la Instrucción Pública», El Siglo Futuro. Diario Católico, 22 de julio de I9r3, p. I. 
Las escuelas de adultos y adultas no son para encontrar en ellas las enseñanzas que se dejaron de recibir ni el ciclo de instrucción elemental que en toda su extensión reciben los alumnos y alumnas en las escuelas primarias, sino una suma de conocimientos que sirvan de base para desenvolver una modesta actividad social... útil en una edad en que la semilla religiosa ha fructificado $\mathrm{ya}^{49}$.

Esta concesión laica a las escuelas de adultas se veía impropia en un país de fuerte tradición católica y la sociedad no estaba todavía preparada para admitir la ausencia de la religión en la enseñanza. Pero esta prerrogativa vino dada porque el Gobierno liberal moderado de Canalejas consideraba contradictorios los preceptos de la libertad de conciencia defendidos en el artículo in de la vigente Constitución de i876 con la obligación de estudiar la doctrina cristiana, de ahí que promulgase alguna normativa que quebrantase esa preeminencia de la Religión en los currículos ${ }^{50}$. En cierta medida era un propósito de Romanones de crear una escuela «neutra» y apartar a la Iglesia del control de la enseñanza pues, como decía: «No había en nuestros propósitos nada contra los principios de la religión católica [...] Se luchaba convencidos de ser absolutamente necesario salir al paso del clericalismo, defender la tolerancia y, sobre todo, mantener la supremacía del poder civil» ${ }^{51}$. Si bien es cierto, la Religión no perdería su importancia en la enseñanza hasta que la II República implanta la educación laica.

La cuestión educativa en la Dictadura de Primo de Rivera tuvo que hacer frente a las corrientes laicas para devolver a la Iglesia su preeminencia en la enseñanza. La cuestión religiosa se convierte en un nuevo pilar para el régimen y la enseñanza de la religión se establece en todos los niveles educativos, aunque dicha medida no estuvo exenta de cierta polémica ${ }^{52}$. En lo que se refiere a la enseñanza de adultas se mantiene el currículo y no llega a explicitarse que haya que impartir la materia de Religión por tratarse de una enseñanza de régimen especial. Ahora bien, el enfoque de la formación de las mujeres estaba impregnado de moralidad y para la adquisición sólida de los valores tradicionales las jóvenes participaban en actividades de carácter benéfico-altruista, asistían a conferencias de temas morales, etc., en definitiva, adquirían contenidos transversales de fuerte sesgo conservador... todo en

49 Sin firmar: La Correspondencia de España: diario universal de noticias, n. ${ }^{\circ} 20153,16$ de abril de 1913, p. 5 .

so Como el RD de 25 de abril de I9I3, en cuyo artículo 2 se indicaba que se eximía del catecismo a los niños cuyos padres profesaran una religión distinta de la oficial del Estado.

s1 Conde de Romanones: Notas de una Vida, Madrid, Marcial Pons, Historia, 1999, p. I33.

${ }_{52}$ Desde i895 la materia de Religión era optativa en los institutos españoles y no había que examinarse de ella para obtener el título. Primo de Rivera la convirtió en obligatoria, pero el Plan Callejo la incorpora tan solo en los dos primeros cursos de bachillerato y daba la oportunidad de que el alumnado pidiese la exención de Religión, por lo tanto, la materia perdía su condición estándar pues tampoco había que examinarse de ella para obtener el título. Esta ambigüedad provocaría malestar tanto en los sectores progresistas como en los conservadores. Vid. Quiroga Fernánez De Soто, Alejandro: «Educación para la ciudadanía autoritaria. La nacionalización de los jóvenes en la Dictadura de Primo de Rivera», Historia de la Educación, 27 (2008), pp. 94-95. 
beneficio de no perder la esencia de la virtud femenina ${ }^{53}$. Pero, con valentía, muchas mujeres aprovecharon la ocasión para avanzar en el terreno educativo y político ${ }^{54}$.

Llegados a este punto y tras el recorrido legislativo de las escuelas de adultas y el análisis de los currículos, podemos ahora preguntarnos qué se sabe de su implantación, de su efectividad, de su aceptación. A priori podemos indicar que la Administración, con sus leyes ambiguas y laxas apelando a la voluntariedad de las maestras y la ayuda de los ayuntamientos, no contribuyó lo suficiente para que se implementaran. Veamos su alcance en la provincia de Ourense donde, sin ninguna duda, serían muy necesarias dados los niveles bajísimos de alfabetización femenina.

\section{Implantación de las escuelas de adultas en la provincia de Ourense}

El analfabetismo femenino era preocupante en toda Galicia y, en concreto, en Ourense. A comienzos de siglo xx la provincia partía de una situación muy desalentadora pues las tasas de mujeres que no sabían leer ni escribir ascendían a un 7I,4\%, siendo de las más elevadas de todo el Estado español. En el tercer decenio se produjo un destacado descenso llegando a un $53 \%$, pero seguía estando de las últimas con respecto a las provincias españolas. Al preguntarnos el porqué del tránsito lento del analfabetismo a la alfabetización de las mujeres orensanas tenemos que buscar la respuesta en la situación depauperada de la enseñanza primaria de la provincia pues, aunque las escuelas no eran muy escasas, estas estaban muy dispersas en pueblos remotos y tenían un funcionamiento muy irregular.

Pero uno de los factores que más pesaba era la mentalidad de la sociedad de la época que consideraba prescindibles los aprendizajes de la escuela para las hijas ya que era prioritario que contribuyesen en las faenas domésticas y agrícolas y su destino era el matrimonio. Esto provocaba el absentismo escolar de las niñas orensanas. Obviamente, con el transcurso de los años hubo en Ourense un incremento de matrícula femenina en la enseñanza primaria, propiciado por un cierto cambio de mentalidad y por las políticas educativas aplicadas en España deseosas de extender la escolarización, hacer cumplir la obligatoriedad de acudir a la escuela y reducir el analfabetismo, pero, aun así, la escolarización femenina siguió por detrás de la masculina y también por detrás de las demás provincias gallegas ${ }^{55}$.

Esta situación tan calamitosa de la educación en Ourense en el primer tercio de siglo preocupaba al ilustre catedrático del Instituto Provincial, Eduardo

53 Sobre los fundamentos educativos del período de la dictadura de Primo de Rivera vid. López Martín, Ramón: Ideología y educación en la dictadura de Primo de Rivera: Escuelas y Maestros, Valencia, Universitat de Valencia, 1994.

${ }_{4}$ Vid. Díaz Fernández, Paloma: «La Dictadura de Primo de Rivera. Una oportunidad para la mujer», Espacios, Tiempo y Forma. Serie V, Historia Contemporánea, t. 17 (2005), pp. 175-190.

"Para conocer el panorama educativo en Ourense y provincia en el primero tercio de siglo vid. Cid Galante, Rosa María: Mujer y educación en Ourense (1900-1930), Tesis doctoral, Vigo, en versión CD por la Universidad de Vigo, 2006; O ensino primario en Ourense no primeiro terzo do século XX, Ourense, Diputación Provincial, 2014. 
Moreno López ${ }^{56}$, quien ya comenzaba a hablar de la necesidad de crear establecimientos para adultos con el fin de paliar la incultura de la provincia. Aunque también se mostraba bastante escéptico pues, según su opinión, no se ponían las políticas adecuadas para asentar dichos establecimientos: «Pero no hay que hacerse grandes ilusiones respecto a la eficacia de esta clase de disposiciones, por desgracia, más frecuentemente eludidas que cumplimentadas ${ }^{57}$.

En efecto, no eran establecimientos de carácter permanente pues no contaban con los suficientes apoyos institucionales y dependía de la voluntariedad de los docentes y de la concurrencia de los jóvenes a las clases. Por ello, casi no hay registros oficiales que ofrezcan información fehaciente de las escuelas para las personas adultas que llegaron a funcionar en Ourense. Se acudió a diversos archivos para dar con una fuente oficial que arrojase datos con garantías; se consultaron las actas de inspección, los expedientes de creación de escuelas, los registros escolares..., pero en ninguna se hacía mención de dichos establecimientos. Por fortuna, el Boletín Oficial de la Provincia de 1908 ofrecía un registro general y detallado de las escuelas públicas por partidos judiciales reflejándose las destinadas a las personas adultas, aunque no venían especificadas por sexo. Con estos datos se elaboró el cuadro siguiente (Cuadro 3):

\section{CuAdro 3. Número de escuelas de personas adultas por ayuntamientos $y$ partidos judiciales en 1910}

\begin{tabular}{|l|c|c|}
\hline & N. $^{\text {O }}$ & \multirow{2}{*}{ Por partidos judiciales } \\
\hline Allariz & 7 & \\
\hline Baños de Molgas & \\
\hline X.de Ambía & \\
\hline X.de Espadañedo & \\
\hline Maceda & 4 & \\
\hline Paderne & 3 & \multirow{2}{*}{33} \\
\hline Taboadela & 2 & \\
\hline Vilar de Barrio & 4 & \\
\hline
\end{tabular}

s6 Eduardo Moreno López era hijo del catedrático de Historia y Geografía del Instituto de Cádiz Alfonso Moreno Espinosa (I840-1905), amigo personal del líder del krausismo español Francisco Giner de los Ríos. Eduardo llegó a Ourense en i897siguiendo los pasos de su gran amigo Julián Besteiro. Ambos aprobaron las oposiciones y comenzaron a trabajar en el Instituto Provincial, pero Julián Besteiro tan solo permaneció dos años para marcharse de nuevo, mientras que Eduardo se afincó para siempre en la ciudad orensana ejerciendo como catedrático de Geografía e Historia en el Instituto orensano. Era un hombre de amplia cultura y convicciones republicanas siendo muy admirado por la sociedad orensana por la promoción de la Universidad Popular en la ciudad. Vid. Benso Calvo, Carmen: «La Universidad Popular de Orense», Sarmiento. Anuario Gallego de Historia de la Educación, n. ${ }^{\circ}$ (1999), pp. 255-295.

57 Moreno López, Eduardo: Medios prácticos para difundir la cultura en la provincia de Ourense, Trabajo premiado en los Juegos Florales celebrados en Ourense el mes de junio de 1906, Barcelona, Tipografía «El Anuario de la exportación», 1908, p. 25. 
LAS ESCUELAS DE ADULTAS EN LOS INICIOS DEL SIGLO XX: ROSA MARÍA CID GALANTE

\begin{tabular}{|c|c|c|}
\hline Bande & IO & \multirow{7}{*}{39} \\
\hline Entrimo & 3 & \\
\hline Lobeira & 3 & \\
\hline Lobios & 4 & \\
\hline Muíños & 9 & \\
\hline Padrenda & 7 & \\
\hline Verea & 2 & \\
\hline O Carballiño & 5 & \multirow{9}{*}{30} \\
\hline Beariz & 3 & \\
\hline Boborás & 5 & \\
\hline Cea & 2 & \\
\hline O Irixo & 6 & \\
\hline Maside & 5 & \\
\hline Punxín & $\mathrm{I}$ & \\
\hline Piñor de Cea & I & \\
\hline San Amaro & 2 & \\
\hline Acevedo & 2 & \multirow{12}{*}{$4 \mathrm{I}$} \\
\hline A Bola & $\mathrm{I}$ & \\
\hline Cartelle & 8 & \\
\hline Celanova & $\mathrm{O}$ & \\
\hline Cortegada & 5 & \\
\hline Freas de Eiras & 3 & \\
\hline Gomesende & $\mathrm{I}$ & \\
\hline A Merca & 9 & \\
\hline Pontedeva & 2 & \\
\hline Quintela de Leirado & 2 & \\
\hline Vilameá & 6 & \\
\hline Vilanova dos Infantes & 2 & \\
\hline
\end{tabular}


LAS ESCUELAS DE ADULTAS EN LOS INICIOS DEL SIGLO XX:

398 LEGISLACIÓN, CURRÍCULO Y JUSTIFICACIÓN. CASO PARTICULAR DE ORENSE ROSA MARÍA CID GALANTE

\begin{tabular}{|c|c|c|}
\hline Baltar & 4 & \multirow{11}{*}{38} \\
\hline Os Blancos & 4 & \\
\hline Calvos de Randín & 3 & \\
\hline Xinzo de Limia & 6 & \\
\hline Moreiras & 2 & \\
\hline Porqueira & 5 & \\
\hline Rairiz de Veiga & 3 & \\
\hline Sandiás & 2 & \\
\hline Sarreaus & 4 & \\
\hline Trasmiras & 4 & \\
\hline Vilar de Santos & $\mathrm{I}$ & \\
\hline Amoeiro & 3 & \multirow{12}{*}{46} \\
\hline Barbadás & 3 & \\
\hline Canedo & 4 & \\
\hline Coles & 5 & \\
\hline Esgos & 3 & \\
\hline Nogueira Ramuín & 3 & \\
\hline Ourense & 6 & \\
\hline Pereiro de Aguiar & 4 & \\
\hline A Peroxa & 3 & \\
\hline San Cibrao & 4 & \\
\hline Toén & 6 & \\
\hline Vilamarín & 2 & \\
\hline Avión & 7 & \multirow{9}{*}{26} \\
\hline A Arnoia & 2 & \\
\hline Beade & I & \\
\hline Carballeda de Avia & 2 & \\
\hline Castrelo de Miño & 2 & \\
\hline Cenlle & 2 & \\
\hline Leiro & 3 & \\
\hline Melón & 3 & \\
\hline Ribadavia & 4 & \\
\hline
\end{tabular}



ROSA MARÍA CID GALANTE

\begin{tabular}{|c|c|c|}
\hline Castro Caldelas & 5 & \multirow{9}{*}{34} \\
\hline Chandrexa & 4 & \\
\hline Larouco & I & \\
\hline Manzaneda & 3 & \\
\hline Montederramo & 4 & \\
\hline Parada de Sil & 3 & \\
\hline San Xoan do Río & 4 & \\
\hline A Teixeira & 3 & \\
\hline Pobra de Trives, A & 7 & \\
\hline O Barco de Valdeorras & 4 & \multirow{7}{*}{32} \\
\hline Carballeda de Valdeorras & 9 & \\
\hline A Veiga & 6 & \\
\hline Petín & 4 & \\
\hline A Rúa & 2 & \\
\hline Rubiá & 4 & \\
\hline Vilamartín de Valdeorras & 3 & \\
\hline Castrelo do Val & 5 & \multirow{8}{*}{27} \\
\hline Cualedro & $\mathrm{I}$ & \\
\hline Laza & 6 & \\
\hline Monterrei & 2 & \\
\hline Oímbra & 2 & \\
\hline Riós & 5 & \\
\hline Verín & 3 & \\
\hline Vilardevós & $\mathrm{I}$ & \\
\hline O Bolo & 2 & \multirow{5}{*}{30} \\
\hline A Gudiña & 2 & \\
\hline A Mezquita & 7 & \\
\hline Viana do Bolo & 15 & \\
\hline Vilariño de Conso & 4 & \\
\hline
\end{tabular}

Fuente: Elaboración propia a partir de «Estadística Escolar de España en I908», Diario Oficial da Provincia, diciembre de i909; enero, febrero y marzo de i9ıo.

En Ourense había en 1908 una oferta bastante considerable para adultos con un total de 366 establecimientos públicos repartidos por toda la provincia. Con casi total seguridad se puede afirmar que se trata de escuelas masculinas de adultos. Los maestros enviaban a la inspección una instancia por medio de la cual le informaba de la puesta en funcionamiento de la escuela de adultos (Fotografía 3), así como el número de alumnos inscritos. Según se pudo comprobar, la asistencia a estas clases era provechosa pues la media de matrícula se situaba alrededor de 
los 22 alumnos. Estaban a cargo de los maestros de la enseñanza diurna obteniendo por ello una gratificación en su sueldo de 250 pesetas. No obstante, frente a la voluntariedad de los docentes estaba una Administración poco considerada pues atrasaba mucho los pagos de las gratificaciones, lo que era motivo de queja por parte de un gran número de maestros de la provincia que no veían recompensados sus esfuerzos.

\section{Fotografía 3. Comunicación de apertura de la escuela de adultos en Pousa}

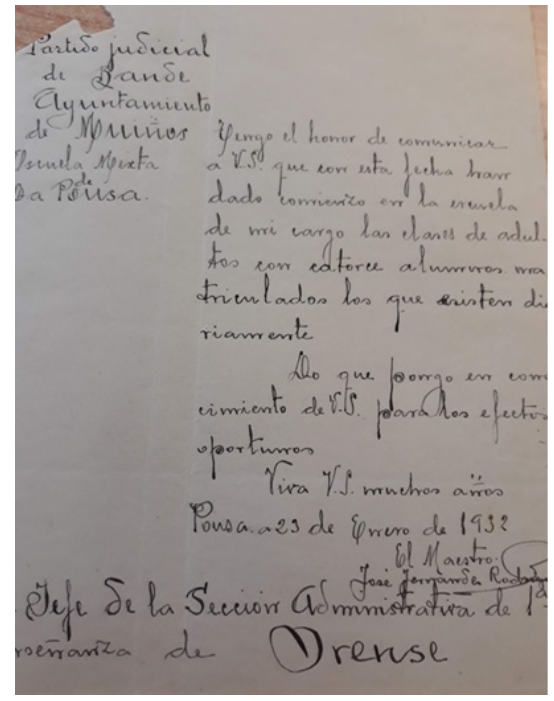

Fuente: AHPOU (Arquivo Histórico Provincial de Ourense), Obligaciones de Primera Enseñanza. Nómina. Caja 885.

El asegurar que se trata de escuelas para adultos es debido a otra fuente que aportó suculenta información, como fueron las nóminas de los docentes ${ }^{58}$. Tras su consulta pudo constatarse que las maestras no regentaban escuelas de adultas pues en sus haberes no se hace indicación ninguna al respecto ni figuran instancias que indicaran su puesta en funcionamiento, como sí sucede en el caso de los maestros. El hecho de no crearlas tal vez sea debido a que no se sentían motivadas para ponerlas en funcionamiento ya que implicaba duplicar su trabajo y econó-

${ }_{58} \mathrm{Al}$ estar buscando información para esta investigación, se localizó casualmente una fuente muy interesante. Se trata de las nóminas del profesorado del año 1932 aunque, lamentablemente, esta aparecía bastante fragmentada e incompleta pues tan solo figuraba de algún partido judicial. Era un documento manuscrito por la Inspección en el que figuraba la retribución a los docentes. En el dosier también figuraban las instancias que enviaban los maestros a la Inspección para informar de la apertura de la escuela nocturna, así como el número de alumnos asistentes, y cuyo fin era que les fuera abonada la gratificación. AHPOU (Arquivo Histórico Provincial de Ourense), Obligaciones de Primera Enseñanza. Nómina. Legajos. Caja 885. 

ROSA MARÍA CID GALANTE

micamente no les compensaba. Cabe pensar también que las destinatarias de estos estudios no manifestaran interés por acudir a unas clases vespertinas y/o nocturnas pues el trabajo en el campo y la vida rural les exigían unos esfuerzos para los que no necesitaban conocimientos académicos.

Como ya se dijo, la escasez de fuentes impidió hacer una serie continua de la evolución del número de escuelas de adultos y adultas en la provincia. Se acudió a los Anuarios Estadísticos y, a pesar de ofrecer unos datos imprecisos e incompletos, algo ayudaron y se elaboró el siguiente cuadro (Cuadro 4).

\section{Cuadro 4. Número de escuelas de adultas y asistencia del alumnado en la provincia de Ourense}

\begin{tabular}{|c|c|c|c|c|}
\hline & $\begin{array}{c}\text { Número de escuelas } \\
\text { de adultos }\end{array}$ & $\begin{array}{c}\text { Número de escuelas } \\
\text { de adultas }\end{array}$ & $\begin{array}{c}\text { Asistencia a } \\
\text { las escuelas } \\
\text { hombres }\end{array}$ & $\begin{array}{c}\text { Asistencia a } \\
\text { las escuelas } \\
\text { mujeres }\end{array}$ \\
\hline I914 & 2 (capital) & 0 & & \\
\hline I916 & 39I & o & 8820 & \\
\hline I929 & No ofrece datos & No ofrece datos & I4532 & 0 \\
\hline I932 & No ofrece datos & No ofrece datos & 17874 & 24 \\
\hline
\end{tabular}

Fuente: Elaboración propia a partir de los Anuarios Estadísticos de España.

Como puede observarse, el número de establecimientos de adultos para el año I9I4 no se correlaciona con los ofrecidos en el Cuadro 3, pues tan solo consta que había dos escuelas en la capital orensana, lo que hace sospechar de la veracidad de dichos datos. Sin embargo, los de 1916 parecen más verídicos indicándose que había 39r escuelas de adultos, que son 25 más que en i908. Lamentablemente, de los años I929 y 1932 no se ofrece el número de escuelas, pero sí se nos informa de la matrícula masculina adulta, lo que da muestras de que seguían funcionando. Si los datos son fiables, en 1932 la asistencia ascendía a i7874, un abultado registro, lo que indica un aprovechamiento de esta enseñanza por parte de los jóvenes. Pero debemos pensar en la irregularidad del funcionamiento de estas escuelas pues dependerían de la concurrencia del alumnado, que con probabilidad diferiría de un año para otro, y también del aguante del maestro para mantenerlas pues percibía tarde y mal la gratificación pecuniaria.

También existía una oferta privada de adultos ${ }^{59}$, tal como pudo comprobarse en los expedientes de solicitud de apertura de escuelas. Don Ricardo López abrió una en el pueblo de Cudeiro; don Vicente López Durán en el pueblo de Pena de Reádegos, en el municipio de Villamarín; don Valentín Castro para el pueblo de Pousada, en el Ayuntamiento de Maside. También en A Pobra de Trives se

59 Para conocer la oferta de enseñanza privada en la provincia de Ourense y sus características puede consultarse Benso Calvo, Carmen y Cid Galante, Rosa María: «A ensinanza privada en Ourense a comezos de século xx», Sarmiento: Revista Galego-Portugnesa de Historia da Educación, n. ${ }^{\circ} 8$ (2004), pp. $43-77$. 
solicitó una de adultos por parte de la congregación de los Hermanos de las Escuelas Cristianas. En Coles, la escuela para personas adultas era sostenida por la Sociedad de Agricultores de Coles. En Ourense capital había clases de adultos en la Escuela Neutral Laica. En realidad, la oferta privada era muy escasa.

En cuanto a la oferta de escuelas adultas tanto públicas como privadas puede decirse que era prácticamente inédita e inexistente. Según los datos que arroja el Cuadro 4, funcionaba alguna escuela adulta en el año 1932 registrándose 24 alumnas, todo hace pensar que se refiere a la Escuela Obrera de mujeres que había en la capital de Ourense.

En efecto, existían en la capital orensana algunos centros de carácter privado que ofrecían enseñanza para las mujeres adultas ${ }^{60}$. Uno promovido por las Hijas de la Caridad ${ }^{61}$, situado en la Rúa Santo Domingo, que tenía una amplia oferta educativa con un sentido filantrópico y en lo referente a la enseñanza de mayores ofrecía instrucción completa de segunda enseñanza y de adorno y refinamiento. La otra institución es la Escuela Obrera Inmaculada Concepción, un centro privado aunque de carácter gratuito, fundado en 1920 por iniciativa de Pura Domerq. Fue directora del mismo Blanca Calvo (Fotografía 4), una ilustre maestra profundamente preocupada por la escasa formación de las jóvenes orensanas. La escuela estaba destinada a las mujeres mayores de is años que acudían en horario nocturno para recibir clases de cultura general impartidas por profesoras voluntarias y futuras maestras, alumnas de la Normal. Además realizaban actividades culturales como recitales públicos, representaciones teatrales, excursiones..., convirtiéndose la escuela en un referente en la ciudad y recibiendo el reconocimiento de la ilustre inspectora Antonia Ortiz Currais, quien exaltaba la gran labor de la escuela obrera pues ofrecía la oportunidad de que las mujeres casi analfabetas adquirieran una buena formación y educación y encontraran un porvenir, lo que sin duda redundaba en el beneficio de toda la sociedad orensana ${ }^{62}$. En la prensa se exaltaban las excelencias de la escuela obrera:

Son muchas, muchísimas, las muchachas que ingresaron en la mencionada escuela sin saber leer ni escribir, y que gracias al esfuerzo y al sacrificio de caracteres heroicos de las bondadosas señoritas que componen el competente profesorado, se hallan hoy en magníficas condiciones para luchar por la vida con armas que son toda una garantía de éxito. Precisamente, hay algunas en nuestra ciudad desempeñando puestos para los que se requiere una preparación que no es corriente hallar, y

60 En los expedientes de creación de escuelas privadas no se encontraron solicitudes de maestras para impartir enseñanza de adultas.

61 Para conocer la obra de las Hermanas de la Caridad en la ciudad de Ourense se recomienda la lectura de un interesantísimo libro cuyo autor es Hernández Figueiredo, José Ramón: Las Hijas de la Caridad en Ourense. Beneficencia y enseñanza (siglo XIX y xx), Ourense, Auriae, 2007.

${ }_{62}$ Sobre la creación y funcionamiento de la Escuela Obrera «Inmaculada Concepción» vid. Cid Galante, Rosa María: «A Escola Obreira Inmaculada Concepción. Unha iniciativa altruísta de comezos de século xx que ofrecía a oportunidade instruír a mulleres adultas da cidade», Revista EDUGA. Revista Galega de Ensino, n. ${ }^{\circ} 78$ (xullo-decembro, 2019). 

ROSA MARÍA CID GALANTE

que, desde luego, no hubieran tenido sin la existencia de la humanitaria institución; que tiene además, otro motivo de admiración, cual es el realizar una importante preparación cristiana en sus alumnas, haciéndolas mujeres piadosas, promesa de buenas esposas y madres ejemplares... ${ }^{63}$.

\section{Fotografía 4. Blanca Calvo Moraza.}

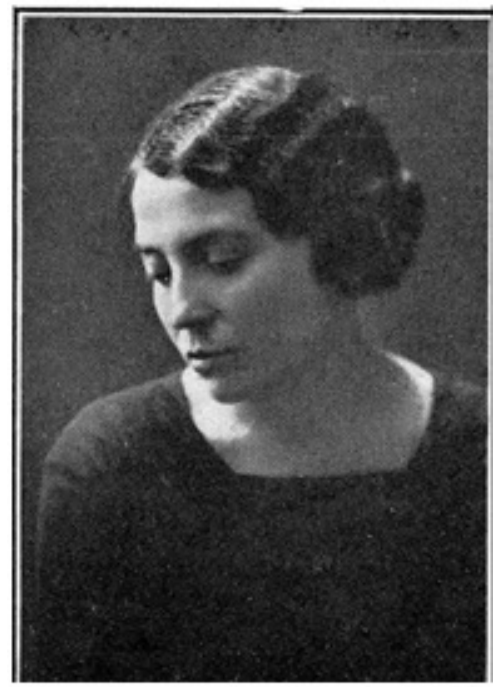

«Blanca Calvo, ilustre pedagoga y literata del grupo escolar Obrero Femenino, institución de gran importancia cultural para las clases trabajadoras Al frente de la cual ha obtenido grandes éxitos y realiza una meritísima altruista labor», Vida Gallega, n. ${ }^{\circ} 523$ (1932).

Pero, tal como acontecía en el resto del Estado español, la enseñanza de adultos y adultas estaba muy desatendida en la provincia de Ourense, y resultaba ser deficiente para los ambiciosos objetivos que se proponía. La eficacia real de estos estudios en todo este tercio de siglo no estaba asegurada y eso hace recordar las impresiones del inspector Salvador de Juan Ponsoda, quien indicaba que, de las sesenta y una escuelas que visitó en 1904, en veintiuna funcionaban clases nocturnas de adultos, aunque no en las condiciones debidas, porque la asistencia a las clases era irregular. Además los docentes tenían que realizar un gran esfuerzo porque muchos de ellos, después de las clases nocturnas, tenían que ir a pernoctar en sus propias casas, a veces muy distantes, ya que los ayuntamientos no les ofrecían habitación, lo que pesaba mucho en el ánimo del personal docente. A esto hay que añadir que para el buen funcionamiento de las clases nocturnas había que establecer sesión única para las diurnas y esto no llegaba a cumplirse

${ }_{63}$ Sen asinar: «La escuela obrera», La Región, 5 de abril de 1934. 
pues los maestros eran poco partidarios de reducir o comprimir la enseñanza de los niños. En otros casos, el problema era por falta de material y el poco apoyo de los ayuntamientos, que solían poner obstáculos y problemas para librarse del sostenimiento de dichas escuelas ${ }^{64}$.

No obstante, estas ideas no eran compartidas por Eduardo Moreno, quien era partidario de exigir más a las instituciones académicas y políticas, a las corporaciones municipales y a las iniciativas privadas para que se implicaran y se esforzaran más en la obra educativa. Era consciente de que la población de la provincia orensana era rural, campesina y estaba diseminada, pero, según él, estos aspectos no debían suponer obstáculos ya que en otros lugares de Europa, con las mismas características, sí pusieron en práctica la educación para adultos. Decía que había que estimular la asistencia del alumnado ofreciendo premios a los más asiduos a las clases o el derecho de preferencia para conseguir un trabajo a aquellos inscritos a los que se controlaría por medio de los registros ${ }^{65}$.

\section{Conclusiones finales}

En el primer tercio del siglo xx se implementaron políticas educativas con el deseo de erradicar los problemas de la educación en España. Las propuestas, las reformas, los planteamientos educativos que tenían como objetivo corregir y modernizar en todos los niveles la enseñanza fueron numerosos en un relativo corto espacio de tiempo, ofreciendo un panorama legislativo de gran complejidad. Pero ya no se trataba solo de ofrecer a las generaciones más jóvenes una formación con garantías, también había que recuperar a aquella población adulta que no tuviera ocasión de formarse adecuadamente, lo que hacía necesario regular y organizar la escuela para adultos y adultas, tal como se estaba planteando en el resto de países europeos preocupados por avanzar en la modernidad.

Las más beneficiadas por esta nueva oferta serían las mujeres, pues siempre quedaron rezagadas en su formación debido a que las leyes para otorgarles derechos y oportunidades siempre vinieron más tarde y con mucho esfuerzo. Las escuelas de adultas supondrían una cura necesaria para recuperar el atraso que muchas padecían. Ahora que en estos años ya se estaban dando avances muy importantes en relación a la escolarización de la mujer en todos los niveles, era preciso mirar hacia aquellas que no habían tenido oportunidades.

Ahora bien, en toda investigación histórica se da el caso de que, al mirar un fenómeno desde nuestra perspectiva actual, lo que en principio parece ser una solución puede que no lo sea tanto. Desde nuestra óptica se puede partir de la premisa de que la apertura de escuelas de adultas en el primer tercio de siglo xx iba

64 Costa Rico, Antón y Gabriel, Narciso de: «La enseñanza primaria en Ourense. Memoria anual del inspector de enseñanza primaria Salvador de Juan Ponsoda (1904)», Sarmiento. Anuario Gallego de Historia de la Educación, n. ${ }^{\circ}$ I (1997), p. 216.

65 Moreno López, Eduardo: Medios prácticos para difundir la cultura en la provincia de $\mathrm{Ou}$ rense... op. cit., pp. $25-32$. 
a permitir, efectivamente, que aquellas mujeres de la época que no acudieran a la escuela primaria adquiriesen conocimientos y formación para luego aprovecharla y abrir sus horizontes. Pero todo depende de cómo se plantee dicha enseñanza.

En este estudio se planteaba la pregunta de si las escuelas de adultas eran una oportunidad de cambio para las mujeres o eran un «más de lo mismo» ya que de nuevo se incidía en aspectos y contenidos que enfatizaban la condición femenina y la misión tradicional a la que estaba destinada. Y, en efecto, dicha enseñanza supuso una permanencia al plantear un currículo con el cual se pretendía formar y perfeccionar su condición de ama de casa y mujer para el hogar. Así mismo, las demandas desde diferentes sectores que reclamaban estos establecimientos para las adultas resaltaban que su finalidad debía ser la de perfeccionar la condición femenina, lo que desanima pensar que ello no condujera a una oportunidad para romper los moldes a los que estaba sujeta. En cuanto a las complementarias sí permitirían un grado de preparación para ciertos oficios (modista, secretaria, dependienta...), es decir, ocupaciones propias para la mujer y aceptados socialmente, pero solo existían en capitales de distrito.

En lo relativo a la creación y funcionamiento de las escuelas de adultas se observó que, pesar de las leyes y normativas, la realidad iba a otro ritmo pues en la provincia de Ourense no llegaron a implementarse. Quizás fuera debido a que la Administración lo dejó en manos de la voluntariedad de las maestras de los pueblos y para ellas no debía resultar muy atractivo el tener que impartir en horario nocturno y tampoco les debió tentar la gratificación honoraria que ofrecían pues era bastante menos que la de sus homólogos.

Efectivamente, suscribiendo a Rumbo Arcas, la puesta en práctica de las escuelas para adultos (se incluyen las adultas) no se resolvió por varias causas: por el carácter nocturno, lo que implicaba cansancio docente; la escasa retribución económica; las condiciones desfavorables; la desacertada orientación de la enseñanza; la reducida duración de las clases, y el pobre concepto que se tenían de estas enseñanzas ${ }^{66}$.

Es innegable que la oferta para la enseñanza de adultos fue un paso importante pues supuso la intención de mejorar la cultura de la sociedad. El primer tercio del siglo xx fue un arranque con imprecisiones legislativas y poca implicación tanto por parte de las instituciones como por parte del profesorado, motivos por los cuales, durante este período, las escuelas, sobre todo de adultas, no tuvieron repercusión. Será en la Segunda República cuando la enseñanza de adultos y adultas se retome con mucha seriedad considerándola un tema de urgencia para conseguir una educación para todos y todas con visos de modernidad.

66 Rumbo Arcas, Begoña: «Política y didáctica de la educación de adultos (I82I-I939)», op. cit., pp. 185 y 194. 
